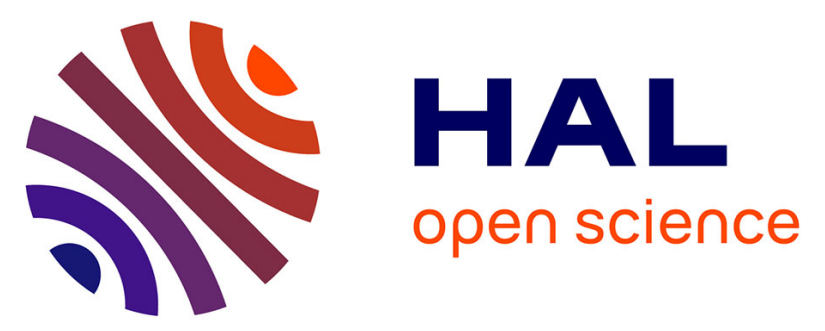

\title{
Mitigation of heterocyclic aromatic amines in cooked meat. Part I: Informed selection of antioxidants based on molecular modeling
}

Maïa Meurillon, Magaly Angenieux, Frédéric Mercier, Patrick Blinet, Laurent Chaloin, Sylvie S. Chevolleau, Laurent Debrauwer, Erwan Engel

\section{To cite this version:}

Maïa Meurillon, Magaly Angenieux, Frédéric Mercier, Patrick Blinet, Laurent Chaloin, et al.. Mitigation of heterocyclic aromatic amines in cooked meat. Part I: Informed selection of antioxidants based on molecular modeling. Food Chemistry, 2020, 331, pp.127264. 10.1016/j.foodchem.2020.127264 . hal-02890485

\section{HAL Id: hal-02890485 \\ https://hal.inrae.fr/hal-02890485}

Submitted on 11 Nov 2020

HAL is a multi-disciplinary open access archive for the deposit and dissemination of scientific research documents, whether they are published or not. The documents may come from teaching and research institutions in France or abroad, or from public or private research centers.
L'archive ouverte pluridisciplinaire HAL, est destinée au dépôt et à la diffusion de documents scientifiques de niveau recherche, publiés ou non, émanant des établissements d'enseignement et de recherche français ou étrangers, des laboratoires publics ou privés. 


\section{Journal Pre-proofs}

Mitigation of heterocyclic aromatic amines in cooked meat Part I: Informed selection of antioxidants based on molecular modeling

Maïa Meurillon, Magaly Angenieux, Frédéric Mercier, Patrick Blinet, Laurent Chaloin, Sylvie Chevolleau, Laurent Debrauwer, Erwan Engel

PII: S0308-8146(20)31126-2

DOI: https://doi.org/10.1016/j.foodchem.2020.127264

Reference: FOCH 127264

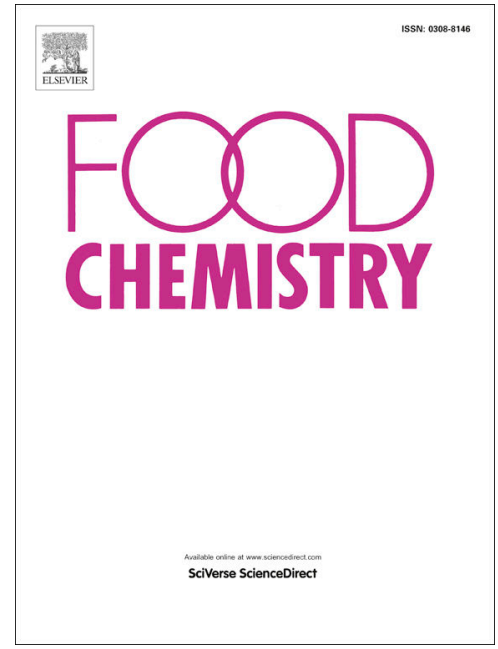

To appear in:

Food Chemistry

Received Date:

5 February 2020

Revised Date: $\quad 4$ June 2020

Accepted Date: $\quad 4$ June 2020

Please cite this article as: Meurillon, M., Angenieux, M., Mercier, F., Blinet, P., Chaloin, L., Chevolleau, S., Debrauwer, L., Engel, E., Mitigation of heterocyclic aromatic amines in cooked meat Part I: Informed selection of antioxidants based on molecular modeling, Food Chemistry (2020), doi: https://doi.org/10.1016/j.foodchem. 2020.127264

This is a PDF file of an article that has undergone enhancements after acceptance, such as the addition of a cover page and metadata, and formatting for readability, but it is not yet the definitive version of record. This version will undergo additional copyediting, typesetting and review before it is published in its final form, but we are providing this version to give early visibility of the article. Please note that, during the production process, errors may be discovered which could affect the content, and all legal disclaimers that apply to the journal pertain.

(C) 2020 Published by Elsevier Ltd. 


\section{Mitigation of heterocyclic aromatic amines in cooked meat}

\section{Part I: Informed selection of antioxidants based on molecular modeling}

6
Maïa MEURILLON ${ }^{1 *}$; Magaly ANGENIEUX ${ }^{1}$; Frédéric MERCIER ${ }^{1}$; Patrick
BLINET $^{1}$; Laurent CHALOIN ${ }^{2}$; Sylvie CHEVOLLEAU ${ }^{3,4}$; Laurent DEBRAUWER $^{3,4}$; Erwan ENGEL $^{1}$

${ }^{1}$ INRAE, UR370 QuaPA, Microcontaminants, Aroma and Separation Science Lab, F-63122 Saint-Genès-Champanelle, France

${ }^{2}$ Institut de Recherche en Infectiologie de Montpellier (IRIM), Université de Montpellier, CNRS, F-34090 Montpellier, France.

${ }^{3}$ Toxalim (Research Centre in Food Toxicology), Toulouse University, INRAE, ENVT, INPPurpan, UPS, F-31027 Toulouse, France

${ }^{4}$ Metatoul-Axiom platform, MetaboHUB, National Infrastructure for Metabolomics and Fluxomics, Toxalim, INRAE, F-31027 Toulouse, France

*Corresponding author: maia.meurillon@inrae.fr 
Abstract:

This work aimed to develop a method permitting an informed choice of antioxidants to reduce carcinogenic heterocyclic aromatic amine (HAA) formation during proteinaceous food cooking. Therefore, a three-step approach was developed. First, the most promising antioxidants were selected using molecular modeling approaches. For this, analog design was used to highlight the most suitable antioxidants based on their diversification potential using bioisosteric replacement. Then, structure activity relationship studies allowed drawing the relevant properties for inhibiting HAA formation and explained partly the inhibitory activity. Secondly, the approved antioxidants were tested in ground beef patties to assess their inhibitory properties against HAA formation. Resveratrol was found to be the most efficient as it totally inhibited MeIQ and reduced MeIQx and PhIP formation by 40 and 70\%, respectively. Finally, natural ingredients rich in these antioxidants were evaluated. Oregano was found to totally inhibit MeIQ formation and to reduce by half MeIQx and PhIP formation.

Keywords: Heterocyclic aromatic amines, mitigation, antioxidants, molecular modeling, analog design, Structure Activity Relationship (SAR), formulation.

\section{Abbreviations}

Heterocyclic Aromatic Amine (HAA); 2-amino-3,4,8-trimethyl-imidazo[4,5-f]quinoxaline (4,8-DiMeIQx); 2-amino-3-methyl-imidazo[4,5-f]quinoline (IQ); 2-amino-3,4-dimethylimidazo[4,5-f]quinoline (MeIQ); 2-amino-3,8-dimethyl-imidazo[4,5-f]quinoxaline (MeIQx); 2-amino-1-methyl-6-phenyl-imidazo-[4,5-b]pyridine (PhIP); 2-amino-3,4,7,8-tetramethyl-3Himidazo[4,5-f]quinoxaline (TriMeIQx). 


\section{Introduction}

52 The preparation and cooking of meat products impact their microbial load, palatability and composition. However, some of these compositional changes such as the formation of heterocyclic aromatic amines (HAAs) have been linked to the promotion of certain cancers (e. g., colorectum, breast, prostate) in meat consumers (Zheng \& Lee, 2009). Recently, the International Agency for Research on Cancer classified red meat and processed meat as probably carcinogenic (group 2A) and carcinogenic (group 1), respectively (International Agency for Research on Cancer, 2018). To reduce HAA impact on human health, mitigation strategies were proposed. Today, one of the most promising approaches is to act on the formulation of red meat products by adding natural antioxidants that limit the formation of HAAs (Meurillon \& Engel, 2016). Although there is a large variety of antioxidants that can reduce HAA formation in meat (Lee et al., 2020), their choice remains mostly empirical. Indeed, the antioxidants tested for HAA inhibition are often chosen arbitrarily because they already display other medicinal properties (Tengilimoglu-Metin, et al., 2017) and are widely used in cooking in a given region. Research works often focused on a particular type of meat or on formulations based on cultural or geographical considerations such as green tea formulation for Chinese research works (Khan, et al., 2017).

To our knowledge, no method for making a reasoned choice exists to date and therefore, there is a real need to develop a well-reasoned mitigation strategy for choosing the best ingredients or preferred diets. The present work hypothesized that medicinal chemistry approaches could help in choosing antioxidants and in explaining their reactivity against HAA formation. A unique and original method based on medicinal chemistry knowledge was therefore developed to choose antioxidants best suited to inhibit HAA formation. This method allowed

74 a rationalization of the choice of antioxidants, which is novel and could be subsequently transposed to other process-induced toxicants such as polycyclic aromatic hydrocarbons. In 
the first part of the paper, an approach adapted from medicinal chemistry and widely used to choose and optimize lead compounds with the help of molecular modeling methods (Andricopulo, Salum, \& Abraham, 2009; Bohacek, McMartin, \& Guida, 1996) was implemented in order to select potent antioxidants for the inhibition of HAA formation. The rationale was to show which known antioxidants would be the most suitable for drug development by the implementation of analog design strategies which rested upon the improvement of existing active molecules to get rid of some side-effects or unwanted properties of the original compound. Analog design (Wermuth, 2010) permitted the discovery of direct analogs (analogs possessing structural and functional similarities), structural analogs (analogs possessing only chemical similarities but presenting different pharmacological properties) and functional analogs (chemically different compounds displaying similar pharmacological properties). Following this selection step, other molecular modeling methods were used to draw the relevant properties required for a good inhibition of HAA formation and explain their reactivity. Then, in the second part, the different antioxidants put forward by the analog design approaches were tested at different concentrations in meat samples in real conditions, using a widely consumed meat product (ground beef patties) prepared by a common cooking method (pan frying) according to WHO recommendations. In the final part, natural ingredients known to be rich in the previous antioxidants were tested under similar conditions in order to take into account complex systems more representative of common culinary practices.

\section{Materials and Methods}

\subsection{Chemicals and standards}

Dichloromethane, acetonitrile and methanol were organic trace analysis grade solvents (Sigma-Aldrich, France). Diatomaceous earth used for the preparation of accelerated solvent 
101 extraction (ASE) cells was obtained from Sigma-Aldrich. Five HAA standards and TriMeIQx

102

103

104

105

106

107

108

109

110

111

112

113

114

115

116

117

118

used as internal standard were obtained from Toronto Research Chemicals (North York, Canada). Resveratrol 99\% and quercetin hydrate 95\% were bought from Acros Organics (Geel, Belgium). Carvacrol (>98\%, FC, FG) and (-)-epicatechin (>90\%, HPLC) were bought from Sigma-Aldrich.

\subsection{Molecular modeling and structure-activity relationship (SAR) studies}

A bibliographic research was performed to identify the active principles known as inhibitors of HAA formation in order to achieve molecular modeling to select the best antioxidants among them (Meurillon \& Engel, 2016). A list of 17 compounds was obtained (figure 1).

To rationalize the selection of the antioxidants for further testing, analog design approaches were used. This strategy relied on the "drug-like" concept (or thereafter the "lead-like" concept) in medicinal chemistry (Lipinski, 2004). To choose between different active compounds having the same biological target, medicinal chemists are looking for their potential of structural diversification by bioisosteric replacement of functional groups, for instance. This would permit in case of synthesis problems, unwanted side-effects or even intellectual property matter to be able to develop quickly and efficiently a new drug with similar activity from the pipeline of the initial drug analogs.

Search for structural analogs based on Tanimoto coefficient. To find new analogs of a drug or as in the present study, antioxidants or natural active principles sharing equivalent inhibitory properties against HAA formation, the most straightforward way is to find new entities with highly similar chemical structures to that of the original compound. Binding and mode of action should be preserved between analogs and original compound. To this end, analogs 
126 based on the high similarity of structural fingerprints measured by the Tanimoto coefficient

127 (describing the ratio of the shared structural elements in respect to the total number of 128 structural elements present in both molecules, Rogers \& Tanimoto, 1960) were searched. This 129 strategy was applied here on the 17 already proven antioxidants (Figure 1) by screening the 130 ZINC (ZINC Is Not Commercial) database (Figure 2a) (Sterling \& Irwin, 2015). The ZINC 131 database encompasses about 230 million purchasable compounds coming from different

132 databanks (natural products, synthetic compounds from chemical companies and Food \& 133 Drug Administration (FDA) approved drugs). The rationale behind this step was that more 134 screened compounds (structurally similar to a studied antioxidant) would lead to more chance 135 of discovering a potent analog (i.e. potent HAA inhibitor). The studied antioxidant with the 136 most analogs would be therefore the most interesting from a biomolecular point of view, as it 137 displayed a large panel of analogs with potentially the same reactivity against HAA 138 formation. This step only relied on atomic composition and the fact that structurally similar 139 molecules would bind to similar targets and therefore display the same biological activity. It 140 permitted the assessment of a number of referenced compounds (in this case from databanks

141 of natural products and FDA approved products) that presented similar structural fingerprints 142 with the studied antioxidants and therefore determined the potential extent of such family to 143 inhibit HAA formation. The Tanimoto index used for this search was set to 0.8 , which

144 indicated $80 \%$ of substructure homology between two molecules and then expanded to 0.7 to 145 broaden the scope of potentially relevant molecules.

147 Functional analog search based on scaffold hopping. To increase the diversity of active 148 molecules with the aim to maintain the inhibitory activity while avoiding side effects, the 149 solution was to look for functional analogues of the known antioxidants. For this purpose, 150 scaffold hopping was used in the present work. This method consisted in the search for 
151 compounds with different core structures but sharing a global 3D shape very similar to the

152 original compound. In medicinal chemistry it allows alternative starting points for lead

153 optimization or to generate backup candidates for advanced compounds. For this purpose, the

154 program LigCSRre (Quintus, Sperandio, Grynberg, Petitjean, \& Tuffery, 2009; Sperandio,

155 Petitjean, \& Tuffery, 2009) implemented on the RPBS (Ressource Parisienne en

156 Bioinformatique Structurale) platform (Alland, et al., 2005) (Figure 2b) combining 3D

157 maximal substructure search and molecular similarity was used. A databank of 2048 active

158 compounds was screened. It permitted determination of a range of new molecules from

159 different families potentially able to show an inhibitory effect on HAA formation. The

160 LigCSRre software returned a list of compounds ranked by similarity scores and a specific

161 file containing the best compounds superimposed onto the query (as to know the studied

162 antioxidants). The similarity score rested especially upon a calculated value, the Zscore, based

163 on the number of shared bonds and considered significant above 2 . In this work, Zscore value

164 was deliberately chosen above 2 in order to only restrict to the best results. However, for

165 antioxidants for which the query did not return results above 3.01, the Zscore was decreased

166 to 2 to evaluate the reply quality at this level of similarity (Supplementary Data 2).

167

168 Pharmacophore models by QSAR. Having identified the most relevant antioxidants, the

169 following step was to explain the reasons why they displayed such inhibitory activity. That

170 implied studying chemical scaffold and associated functional groups. This approach used the

171 pharmacophore concept. A pharmacophore is an abstract description of molecular features

172 that are necessary for molecular recognition of a ligand by a biological macromolecule. In

173 medicinal chemistry, the establishment of a pharmacophore model allows definition of all

174 parts of a molecule that are necessary for its biological activity. A pharmacophore model

175 explains how structurally diverse ligands can bind to a common receptor site. Knowing that, it 
176 becomes easier to develop new analogs possessing the same targeted activity. Typical

177 pharmacophore features include hydrophobic centroids, aromatic rings, hydrogen bond

178 acceptors or donors, cations and anions. The features need to match different chemical groups

179 with similar properties, in order to identify novel ligands. A well-defined pharmacophore

180 model includes both hydrophobic volumes and hydrogen bond vectors. In computational

181 chemistry, pharmacophores are used to define the essential features of one or more molecules

182 with the same biological activity and serve as the starting point for developing 3D-QSAR

183 models useful in drug discovery. In this research work, the pharmacophore model was built

184 after superposing validated antioxidants from the same structural family using the ZINC

185 PHARMER tool (Koes \& Camacho, 2012). The model was created based on physicochemical

186 properties of the selected antioxidants as to know hydrophobicity, aromaticity, donor or

187 acceptor of hydrogen bonds, ionic or electrostatic bonds and used for screening the ZINC 188 database (Figure 2c).

190 Electrostatic potential surface computation. To increase the chance of discovering highly

191 similar compounds, another important component was added, the electrostatic potential

192 surface distribution. Indeed, to be able to compare different structurally similar compounds to

193 our selected antioxidants, the electrostatic surface was representative of both the electronic

194 distribution within aromatic cycles and partial charges of each atom. For structure-based drug

195 design, the visual representation of electrostatic potentials provides insights into protein-

196 ligand interactions, and hence can play a major role in elucidating the relationship between

197 structure and reactivity of a biomolecular system. Nowadays, colorful plots of electrostatic

198 potential are used in drug design to rationalize trends in organic reactivity and binding in

199 host-guest complexes. In the present work, the different antioxidant molecules were modeled

200 with Vega ZZ version 3.1 which allowed in particular charge assignment and energy 
minimization necessary for the computation of surface electrostatic potentials. This was computed using APBS (“Adaptive Poisson-Boltzmann Solver") plugin tool implemented in the PyMol Molecular Graphics System, Version 1.3, Schrodinger, LLC. From this calculation,

204 the positive and negative isosurfaces were contoured at +5 and $-5 \mathrm{kT} / \mathrm{e}$, respectively (Figure $2052 \mathrm{~d})$.

\subsection{Meat sample preparation}

208 Ground beef was obtained from Société Convivial (Gannat, France). The meat was certified 209 from Charolais cattle and contained $11 \%$ fat. Stored at $-80{ }^{\circ} \mathrm{C}$, it was thawed overnight in the 210 fridge at $4{ }^{\circ} \mathrm{C}$ one day before use.

211 The four natural products rich in phenolic antioxidants were found at the local supermarket:

212 'Extra Fine Capers' from Maille (France), Pinot Noir Burgundy wine bottles, organic green tea in bags from Naturela and dried oregano from Ducros. They were added in two ways:

214 marinated or blended in. For red wine and green tea samples, the meat patties were fully 215 marinated in each solution for 2, 4 or 6 hours. For the caper and oregano samples, as well as 216 for the four pure chemical compounds, the necessary amount of antioxidant $(0.1 \%, 0.25 \%$ and $2170.5 \%$ mass concentration) was first manually ground in a stainless steel mortar and then added 218 to meat patties and mixed four times for 20 seconds. After mixing, patties of $26 \mathrm{~g}$ of the same 219 dimension were shaped with a round stainless steel ring. The patties were vacuum sealed and 220 stored at $-18^{\circ} \mathrm{C}$.

221 Marinade durations were chosen according to literature data on marinated meat (Busquets, 222 Puignou, Galceran, \& Skog, 2006; Melo, et al., 2008) to induce a decrease in HAAs while 223 being realistic with common household practices. Concentrations in active principles and 224 natural ingredients were chosen to be realistic from a consumer point of view: high enough to 
display a potential inhibitory effect based on literature data (Gibis \& Weiss, 2012; Friedman,

226 Zhu, Feinstein, \& Ravishankar, 2009) but low enough to be accepted in meat recipes.

227 For each formulation and concentration, 3 samples were prepared and further cooked and 228 tested for HAA levels.

\subsection{Cooking method}

231 To study the formation of HAAs during cooking, ground beef patties were cooked in a stainless steel frying pan (17 cm diameter) on a controlled-temperature induction hob (Bosch Electroménager, Saint-Ouen, France) according to the method described by Planche et al. (2017). A sheet of $11 \mu \mathrm{m}$ thick aluminum foil was laid on the bottom of the frying pan to recover juice released during meat cooking. Cooking conditions were used to simulate medium meat (core $70{ }^{\circ} \mathrm{C}$, according to WHO recommendations for ground meats). According to Planche et al. (2017), these cooking conditions corresponded to 14 min heating (turned over three times) at $200{ }^{\circ} \mathrm{C}$ at the bottom of the pan. Temperatures at the core of the meat and at the bottom of the pan were monitored by thermocouples (RS Components, 240 Beauvais, France).

\subsection{Quantification of HAAs in ground beef patties}

243 Five different HAAs (IQ, MeIQ, MeIQx, 4,8-DiMeIQx, PhIP), likely to be found in meat,

244 were determined by ultra-high-performance liquid chromatography-atmospheric pressure 245 chemical ionization-tandem mass spectrometry (UHPLC-APCI-MS/MS) based on a liquid 246 chromatography-atmospheric pressure chemical ionization-tandem mass spectrometry (LC247 APCI-MS/MS) method developed for chicken meat (Chevolleau, Touzet, Jamin, Tulliez, \& 248 Debrauwer, 2007) and since adapted for analyzing beef samples (Kondjoyan, Chevolleau, 249 Greve, et al., 2010). The choice of APCI was based on a previous work (Chevolleau, S., et al., 
2007) which showed that positive APCI was better suited than ESI for the detection of 10

251 HAAs. These results were in agreement with other published works (Guy, Gremaud, Richoz,

\& Turesky, 2000) and were further confirmed for all the studied HAAs. However, it should be noted that several papers also describe ESI-based analytical methods for HAA analysis, since ESI is much more widespread than APCI in laboratories.

Briefly, $1 \mathrm{~g}$ of lyophilized ground beef sampled from the whole cooked sample was first treated with $1 \mathrm{M} \mathrm{NaOH}$ for protein denaturation. After accelerated solvent extraction (ASE)

(addition of $11 \mathrm{~g}$ of diatomaceous earth, extraction with dichloromethane) and purification of

the extract, the resulting residue was re-dissolved in $200 \mu \mathrm{L}$ of the starting $\mathrm{LC}$ mobile phase. Separation was performed on an Accela 600 LC system (Thermo Fisher Scientific, France), using a Hypersil GOLD C8 column (Thermo Fisher Scientific, $50 \times 2.1 \mathrm{~mm}, 1.9 \mu \mathrm{m}$ ) with prefilter. Five microliters of the final extract were injected, and separation was performed at $30{ }^{\circ} \mathrm{C}$ at a flow rate of $0.5 \mathrm{~mL} / \mathrm{min}$. Chromatographic separation was achieved using mobile phases composed of $\mathbf{A}: \mathrm{AcONH}_{4}(30 \mathrm{mM}, \mathrm{pH} 6) / \mathrm{CH}_{3} \mathrm{CN} / \mathrm{CH}_{3} \mathrm{OH}(2 / 1)(90 / 10$, v/v) and $\mathbf{B}$ : $\mathrm{AcONH}_{4}(30 \mathrm{mM}, \mathrm{pH} 6) / \mathrm{CH}_{3} \mathrm{CN} / \mathrm{CH}_{3} \mathrm{OH}(2 / 1)(10 / 90, \mathrm{v} / \mathrm{v})$. The elution gradient was as using positive APCI based on two specific transitions for each HAA. Typical working parameters were as follows: discharge APCI current, $3 \mu \mathrm{A}$; nebulizer temperature, $420{ }^{\circ} \mathrm{C}$; heated transfer 271 capillary temperature, $260{ }^{\circ} \mathrm{C}$; sheath gas flow rate, 35 a.u.; auxiliary gas flow rate, 10 a.u. The 272 performance of the optimized method was characterized in terms of linearity $\left(r^{2}>0.98\right.$ between 1 and $500 \mathrm{pg} / \mu \mathrm{L}$ ) with relative concentration residual deviation lower than $15 \%$ (20\% LoQ-level) for all the concentration levels of the calibration curve), measure repeatability $(\mathrm{CV}>15 \%)$ and relative bias 
LoD was defined as the lowest concentration of analyte that could be detected with acceptable

277 chromatographic peak shape, with quantification and confirmation ions present with a signal-

278 to-noise ratio $(\mathrm{S} / \mathrm{N})$ greater than 3. The LoQ was the lowest concentration that met the LoD

279 criteria, but with a S/N of 10 and both bias\% and relative standard deviation (RSD) below

$28020 \%$. Both the LoD and LoQ have been precisely determined for each of the HAAs. However,

281 for convenience reasons, the LoQ was set at the value of $1 \mathrm{pg} / \mu \mathrm{L}$, which was common to all

282 the 5 HAAs and corresponded to the lower point of the calibration range. Since APCI may be

283 subject to signal suppression or enhancement due to co-extracted matrix constituents,

284 evaluation of matrix effects (ME) was carried out by comparing the calibration curves

285 obtained by a calibration range in the solvent and in the matrix $(n=3)$. ME $(\%)=(($ matrix

286 range slope/solvent range slope $)-1) \times 100$. In this context, matrix effects were interpreted as

287 follows: negative and positive values for ME highlighted matrix-induced suppression and

288 enhancement, respectively. Between $-20 \%$ and $20 \%$ the ME was considered small, between -

$28950 \%$ and $-20 \%$ or $20 \%$ and $50 \%$ the effect was medium, and for values of ME below $-50 \%$ or

290 higher than $50 \%$ the effect was considered strong. The matrix effects precisely determined for

291 each of the HAAs were less than $20 \%$ and could be considered negligible. Each cooked meat sample

292 was extracted and analyzed in triplicate. HAA contents were expressed in nanograms of compound per 293 gram of freeze-dried product.

\subsection{Data analysis}

296 Data were analyzed using Statistica software 10.0 (Statsoft, Maisons-Alfort, France). To

297 determine whether the formulation (antioxidant or natural ingredient) had an effect on the 298 level of HAAs in cooked meat, a one-way analysis of variance (ANOVA; $p<0.05$ ) was 299 performed on data from UHPLC-APCI-MS/MS analyses. A Dunnett mean comparison test 300 was then performed on the resulting dataset, to determine which formulation concentration 301 was distinct from the control sample $(p<0.05)$. When a significant difference was found, a 
302 Duncan mean comparison test was performed on the dataset to differentiate the concentrations

303 of a given antioxidant $(p<0.05)$.

304

\section{Results and Discussion}

\subsection{Choice of relevant antioxidants by molecular modeling}

307 The first part of this study was dedicated to adapting methods used for drug design in 308 medicinal chemistry to select promising antioxidants and explain their inhibitory activity. The 309 rationale behind this approach was, given known inhibitors of HAAs, 1) which ones would be 310 retained as good drug candidates in medicinal chemistry and 2) how to explain their inhibitory 311 activity.

312 Figure 1 shows a list of 17 antioxidants of different families chosen for this study based on a 313 previous review work of literature data on antioxidants known to be HAA inhibitors 314 (Meurillon \& Engel, 2016).

315 The next step relied on the "drug-like"/"lead-like" concept of medicinal chemistry. The 316 rationale to choose antioxidants for HAA inhibition would therefore be linked to their 317 potential diversification. This suggested that many other natural or synthetic compounds 318 could play a similar inhibitory role than these known antioxidants. The selected strategy was 319 based on analog design approaches consisting of modifying an existing active molecule in 320 order to prepare a new molecule showing chemical and/or biological similarity to the original 321 model compound (with the aim for example in the present case to limit the impact on meat 322 organoleptic qualities and to deal with consumer acceptance issues). Thus, the more an 323 antioxidant would display analogs, the more it would be suitable for further inhibition experiments. Indeed, an antioxidant inhibitor of HAA formation may present an aroma default 
326 permit discovery of other compounds as inhibitors but less problematic from an organoleptic point of view. The results from analog design approaches are presented in Table 1.

Concerning closely-related analogs, Figure 1 already displayed such compounds among

known inhibitors of HAA formation. Epigallocatechin and epicatechin are direct analogs as they display structural and functional similarities, as do cafestol and kahweol. However, if the success likelihood (i.e. inhibitory effect against HAAs) is relatively high using one or the other direct analog, the chance to circumvent secondary effects would be low as the molecules are similar.

Structural analogs for the different antioxidants studied are displayed in Table 1. These results already showed that rutin and allicin could be discarded from this study as they displayed a poor diversification potential (i.e. no structural analogs) and therefore a poor "drug-like" potential. The detailed results obtained for all the targeted antioxidants were reported in Supplementary Data 1. As an example, the similarity search done for quercetin 341 gave a list of 26 different referenced compounds. The variability was mostly displayed by the 342 presence of other functional groups such as chloride-like in ZINC299830137 or hydroxyl-like 343 in myricetin (ZINC3874317) or the replacement of one hydroxyl of quercetin by another 344 reactive group such as sulfate-like in quercetin 3'-sulfate (ZINC14644472) or methoxy like in 345 tamarixetin (ZINC6484604). This study evidenced that a lot of close compounds existed with 346 little modification as the main differences lied in functional groups and substituting positions.

347 This suggested that many other natural or synthetic compounds could play a similar inhibitory 348 role than these known antioxidants with however the inconvenience that the $3 \mathrm{D}$ structure was 349 not taken into account. 
Functional analogs were then searched for and are also presented in Table 1. These analogs could display some equivalent functionalities (such as potentially similar inhibitory effects) with wide structural diversity. The method used was scaffold hopping which considered 3D structural similarity. Table 1 summarizes the data found for the different antioxidants studied and confirms the conclusion of the previous step, that rutin and allicin could be discarded for the rest of the study since they do not present any functional analogs. Carnosol, carnosic acid, rosmanol, cafestol, kahweol, epigallocatechin gallate, vitamin E, pyridoxamine and diallyl sulfide can also be dismissed from the study as they did not display results above 3.01 (and few above 2). Supplementary Data 2 show the detailed results obtained for all the targeted antioxidants. As an example, quercetin displayed 4 compounds with a Zscore above 3.01. From the 3D representation, it appeared that the similar active site was the bicyclic part of the molecule as the superimposition of the antioxidant and the found compounds was optimal for this part of the molecule and of less good quality for the other parts.

Therefore, based on the similarity search and the scaffold hopping step, resveratrol, luteolin, quercetin, carvacrol, epigallocatechin and epicatechin displayed the most "drug-like" potential as they presented a large capacity for improvements given the number of structural and functional analogs they possessed.

To determine the relevant properties for a good inhibitory potential, pharmacophore studies were realized based on the antioxidant structures the most "drug-like" (i.e. resveratrol, luteolin, quercetin, carvacrol, epigallocatechin and epicatechin). The aim of this step was to define which functional groups were necessary for antioxidants to exhibit HAA inhibitory properties, which came back to define the functional groups necessary for molecular recognition of a ligand by a biomolecule. Using dedicated software, the pharmacophore study 
was done for quercetin and luteolin (Supplementary Data 3) with the use of different databases of bioactive products. The different properties of these two antioxidants focusing on hydrophobicity, aromaticity, donor or acceptor of hydrogen bonds, ionic or electrostatic bonds were studied by running the software with these data. This highlighted that these two antioxidants were described by the same pharmacophore model and most importantly that three hydrophobic regions and two of hydrogen bonds were the basis of this pharmacophore model (Supplementary Data 3). This was most probably a prerequisite to promote significant inhibitory activities against HAA formation.

To try to explain the reactivity of the selected antioxidants, their electrostatic potential surfaces were computed (Supplementary Data 4). Bicyclic scaffolds of both quercetin and luteolin displayed an important positive electrostatic potential in opposition to the meta hydroxyl groups which were strongly electronegative. So finally, quercetin and luteolin displayed a similar representation of electrostatic field thus explaining their similar reactivity. Both quercetin and luteolin belong to the flavonoid family of polyphenolic antioxidants, are among the most prevalent in fruits and vegetables and among the most potent flavonoids from natural origin for their in vitro biological activity. They also displayed similar pharmacophore results and electrostatic potential representation. Therefore, to select which one will be studied in the rest of this research work, the price argument was used. Looking at SigmaAldrich quotation for these two active principles, it appeared that quercetin was much more available (different kinds of packaging, of purity, etc.) and more than a thousand times less expensive than luteolin for a similar purity (>95\%). Quercetin was therefore selected for the rest of this research work.

Concerning the choice of catechin antioxidant for the next step of the study, it appeared that epicatechin was most promising as it displayed better results in term of similarity search and 
401

402

403

404

405

406

407

408

409

410

scaffold hopping results. From a pecuniary point of view, epicatechin also remained the less expensive. Epicatechin was therefore selected for the following steps of the study.

The selection of carvacrol and resveratrol was less ambiguous as they were the only representatives of their analog family.

As the result of these molecular modeling approaches, four antioxidants were selected to be tested for the inhibition of HAA formation: carvacrol, resveratrol, (-)-epicatechin and quercetin.

\subsection{Assessment of the selected antioxidants on HAA formation inhibition}

The inhibitory properties against HAA formation of the four antioxidants given by the analog design approaches were assessed. For each of them, three different concentrations were tested to evaluate the dose/answer effect. Based on litterature reviews (Alaejos \& Afonso, 2011; Dong, Xian, Li, Bai, Zeng, 2020), this work focused on five thermic HAAs known to be found in pan fried ground beef patties: PhIP, IQ, MeIQ, MeIQx, and 4,8-DiMeIQx.

Table 2 shows the contribution of individual HAAs in each formulation. Control sample (ground beef patty without any antioxidant) exhibited clearly four thermic HAAs: MeIQ, MeIQx, 4,8-DiMeIQx, and PhIP, but no IQ. Their amounts were similar to those reported by other groups for pan-fried ground beef patties as summarized by Alaejos \& Afonso (2011). In the present study, PhIP level in the control meat sample was found to be $1.3 \mathrm{ng} / \mathrm{g}$ of cooked meat and in litterature reviews, it ranged between 0 and $32 \mathrm{ng} / \mathrm{g}$ for pan-fried ground beef patties. IQ and MeIQx levels ranged from 0 to $7-8 \mathrm{ng} / \mathrm{g}$ of cooked meat in other research studies and were found to be not detected and $4.0 \mathrm{ng} / \mathrm{g}$, respectively, in this work. As for 4,8DiMeIQx and MeIQ, their levels ranged from 0 to $3 \mathrm{ng} / \mathrm{g}$ based on litterature review and here reached $0.4 \mathrm{ng} / \mathrm{g}$ and $0.2 \mathrm{ng} / \mathrm{g}$ of cooked meat respectively. 
PhIP inhibition. Carvacrol and resveratrol were the most effective antioxidants tested here to

426

inhibit PhIP formation. Carvacrol at $0.25 \%$ inhibited PhIP formation by $51 \%$ while resveratrol at $0.25 \%$ inhibited $\mathrm{PhIP}$ formation by $71 \%$. Quercetin and epicatechin needed higher concentrations to display an inhibitory effect. At a concentration of $0.5 \%$ of epicatechin $61 \%$ inhibition was observed but none at lower concentrations (0.1 and 0.25\%). Similarly, the present study showed that quercetin at $0.5 \%$ tended towards reducing by half $\mathrm{PhIP}$ formation (54\% of inhibition). This result was in accordance with several other research works (Cheng, Chen, \& Wang, 2007; Oguri, Suda, Totsuka, Sugimura, \& Wakabayashi, 1998; Zhu, et al., 2016) on model systems or on beef patties and using higher concentrations of this flavonoid that induced inhibition ranging from 40 to $75 \%$ of $\mathrm{PhIP}$ formation. Zhu et al. (2016) found that the presence of a hydroxyl group at different positions, especially the B-ring and C-ring of the flavone skeleton, like in quercetin, significantly affected flavonoid inhibition effects on PhIP formation. Thus, they suggested that the simultaneous occurrence in quercetin of a hydroxyl group at 3'-position of B-ring and 3-position of C-ring would greatly enhance the resultant inhibition effects on PhIP formation. Salazar et al. analyzed the role of various phenolic compounds on the PhIP produced in model systems to highlight the structural characteristics that favored the inhibition of this HAA formation (Salazar, Arámbula-Villa, Hidalgo, \& Zamora, 2014). Among these compounds, they studied resveratrol, epicatechin and quercetin. At a concentration of $10 \mu \mathrm{mol}$ of phenolic compound (equimolar with phenylalanine, the main precursor of PhIP), they found that resveratrol was a better inhibitor of PhIP formation than quercetin and that epicatechin was the weakest inhibitor among the three. The three of them have two hydroxyl groups in the meta position of the A-ring but the difference of activity could be explained by the two hydroxyl groups in the ortho position of the B-ring for quercetin and epicatechin. 
The present results in pan-fried ground beef patties confirmed those obtained in model systems by Salazar et al. (2014), as a better inhibition of PhIP was observed for resveratrol than for quercetin and epicatechin. The similar results observed for epicatechin $(61 \%$ inhibition at $0.5 \%$ ) and quercetin (54\% inhibition at $0.5 \%$ ) in this study could be explained by their similar 3D structure (Supplementary Data 5). In the same way, as shown in

454 Supplementary Data 6, quercetin and epicatechin displayed similar representation of their 455 electrostatic potentials. Their bicyclic scaffold displayed an important positive electrostatic potential in opposition to the meta hydroxyl groups which were strongly electronegative. The hydroxyl group of resveratrol and carvacrol displayed the same electronegative potential but contrary to the other two antioxidants, their scaffolds also displayed electronegative potential. The electronegative potential around the hydroxyl group explained its reactivity with the

460 Strecker aldehyde intermediates of HAA formation.

To explain this reactivity, a mechanism was proposed in Figure 3 based on the work of Cheng phenylacetaldehyde, which is the key intermediate in this HAA formation (Cheng, et al., 2009). It rested upon an electrophilic substitution of phenylacetaldehyde by the A-ring (C-6 or C-8) of quercetin, (-)-epicatechin and resveratrol. The electron-withdrawing property of the conjugated carbonyl at the C-ring of quercetin could explain its lack of reactivity with the

467 Strecker aldehyde. The highest reactivity of resveratrol could be explained by a lower steric 468 hindrance as well as the repartition of its electrostatic field as displayed by our modeling 469 (Supplementary Data 4). Carvacrol, a monophenolic compound substituted by alkyl groups was by far less reactive for this kind of reaction as alkyl groups, donors by inductive effect, 471 were less activating than hydroxyl (donor by conjugation) and therefore less ortho/para 472 director. The results of inhibition tests coupled to molecular modeling and structure-activity 473 relationship studies showed the importance of a polyphenolic scaffold with hydroxyls in the 
meta position to activate the electrophilic substitution sites. From the experimental results,

steric hindrance and electron-withdrawing grouping near the A-ring had a negative effect on the inhibitory properties of the antioxidants. Studies of the electrostatic field representation allowed to think that the reactive hydroxyl groups should be surrounded by negative isosurface especially around the carbon involved in the electrophilic substitution and the repartition of the electrostatic fields should be somewhat linear to promote the reaction. This fact accounted for the difference of inhibitory properties between carvacrol and resveratrol on one hand and quercetin and epicatechin on the other.

MeIQx inhibition. MeIQx was found in larger quantities $(p<0.01)$ in ground beef samples as found by $\mathrm{Ni}$ et al. (2008). Of the four antioxidants studied, resveratrol and carvacrol were the most promising to inhibit MeIQx formation at the concentrations tested. At $0.25 \%$, resveratrol inhibited MeIQx by $40 \%$. Carvacrol at $0.25 \%$ permitted an inhibition of $33 \%$ of MeIQx formation. A previous study interested in antibacterial and HAA inhibitory properties of carvacrol in grilled ground beef patties described inhibition level of $72 \%$ for MeIQx (Friedman, et al., 2009) but the concentration used (1\% w/w) was more than in the present study $(0.1,0.25$ and $0.5 \% \mathrm{w} / \mathrm{w})$. 4,8-DiMeIQx inhibition. 4,8-DiMeIQx, as MeIQx, belongs to the quinoxaline type of HAAs and is most probably formed via a dialkyl pyrazine radical intermediate. Therefore, one would have expected similar inhibition results for MeIQx and 4,8-DiMeIQx at least in term of antioxidants having inhibitory properties. In the present work none of the antioxidants studied

494 displayed inhibitory activity against 4,8-DiMeIQx. These results are in accordance with other 495 research studies, such as the work of Zeng et al. (2016) that showed no inhibition of 4,8DiMeIQx by quercetin in a model system even at a concentration higher than in the present study. It could be thus postulated that either the levels of antioxidants employed were too low 498 to imply an inhibitory activity against 4,8-DiMeIQx or as the amount of 4,8-DiMeIQx was 
lower than that of MeIQx, it was difficult to follow such a small variation in quantity. MeIQ

500

501

502

503

inhibition. The best results in HAA inhibition by antioxidants were obtained for MeIQ.

Resveratrol even at the lowest concentration (0.1\%) inhibited totally MeIQ formation.

Epicatechin at a concentration of $0.25 \%$ or $0.5 \%$ achieved the same result. Concerning quercetin, a higher concentration $(0.5 \%)$ was required to totally inhibit the formation of this HAA. Carvacrol was not found to inhibit MeIQ formation at the concentrations used in this study but Friedman et al. described an inhibitory effect of $58 \%$ at a higher concentration (1\% w/w) (Friedman, et al., 2009).

Based on the present results, resveratrol was found to be the most potent antioxidant tested as it inhibited totally the formation of MeIQ, and by 40 and $71 \%$ the formation of MeIQx and PhIP, respectively.

\subsection{Assessment of the inhibitory properties of the natural products rich in the chosen} antioxidants on HAA formation in cooked meat

To each active principle studied was associated a natural product known to be rich in that antioxidant in order to determine the inhibitory potential against HAA formation of the antioxidant pure or in a mixture found in nature and used in household preparations. Thus in parallel to resveratrol, epicatechin, quercetin and carvacrol studies for HAA inhibition, red wine, green tea, caper and oregano formulations, respectively, were investigated. Different concentrations and marinade times were chosen to be representative of consumer's practices and high enough to display a potential inhibitory effect based on litterature data (Gibis \& Weiss, 2012; Friedman, Zhu, Feinstein, \& Ravishankar, 2009) but low enough to be accepted in meat recipes.

Table 3 shows the contribution of individual HAAs in each formulation. 
PhIP inhibition. Concerning natural products rich in antioxidants, oregano (rich in carvacrol)

at higher concentrations $(0.25 \& 0.5 \%)$ had a tendancy to decrease $\mathrm{PhIP}$ formation by more than two fold (60 and 54\% inhibition, respectively). This result agreed with those described by Damašius et al. (2011) which showed a similar range of inhibitory effect of oregano on PhIP formation. The range of $\mathrm{PhIP}$ inhibition with oregano was also in accordance with the results found for carvacrol in the previous part of this work $(51 \%$ of $\mathrm{PhIP}$ inhibition at a concentration of $0.25 \%$ ). From the results of Quelhas et al. (2010), a better inhibition of PhIP formation was expected for green-tea-based formulations but in their work $\mathrm{PhIP}$ control level was higher. The difference in reactivity could be explained by the variable content in active ingredient in food matrices. Indeed, as shown by Henning et al. (2003) the content of epicatechin in green tea varied from 6.5 to $15.4 \mathrm{mg} / 100 \mathrm{~mL}$ among similar kinds of green tea and from $0 \mathrm{mg} / 100 \mathrm{~mL}$ in decaffeinated green tea to $19.7 \mathrm{mg} / 100 \mathrm{~mL}$ in green tea supplement. This variation could explain the differences observed from one study to another, especially since in the previous part of this study, the active principle (epicatechin) at a concentration of $0.5 \%$ displayed an inhibition of $\mathrm{PhIP}$ formation of $61 \%$. From the results of Busquets et al. (Busquets, et al. 2006; Melo, et al., 2008), better inhibition results for red wine were expected but the lower inhibitory effect observed could be potentially explained by confounding factors including the meat matrix used, the red wine used (different antioxidant content depending on the wine), the duration of marinade. Indeed, as was the case for green tea, the level of resveratrol in similar wines (pinot noir) could vary from 2.3 to $10.5 \mathrm{mg} / \mathrm{L}$ according to its geographical origin (Stervbo, Vang, \& Bonnesen, 2007). This explained the difference of reactivity found between resveratrol (inhibition of $71 \%$ at a concentration of $0.25 \%$ ) and red wine (no inhibition).

MeIQx inhibition. Poor MeIQx inhibition was observed with the natural ingredient formulations. Oregano could be the most inhibiting among the products tested as at a 
concentration of $0.25 \%$, it inhibited by $36 \%$ MeIQx formation. This result was similar to the

inhibition found with carvacrol at $0.25 \%$ (33\% inhibition). Contrary to resveratrol, red wine

did nott exhibit inhibitory properties against MeIQx formation, which again could be due to

variation of resveratrol content among pinot noir red wines or the existence of antagonist

effects with other red wine constituents. Green tea seemed to display no inhibitory effect,

which was in accordance with the results found by Quelhas et al. (2010), who observed no

554 reduction of MeIQx for marinated meat samples during 1 to $6 \mathrm{~h}$ in green tea. The absence of inhibition of MeIQx observed for caper and green tea was in agreement with the results found for quercetin and epicatechin, respectively, in the previous part of this study.

DiMeIQx formation. These results were in accordance with previous studies revealing that wine (Melo, et al., 2008) and green tea (Quelhas, et al., 2010) marinades were poor inhibitors of 4,8-DiMeIQx formation in pan-fried beef. They were also in agreement with the lack of inhibition found for the different active principles in the previous part of this work.

MeIQ inhibition. Green tea and oregano were the best natural products tested in this work to

563 inhibit MeIQ formation. The addition of $0.25 \%$ or more of oregano inhibited totally MeIQ

564 formation. As for green tea, $2 \mathrm{~h}$ or $4 \mathrm{~h}$ marination totally inhibited MeIQ formation, while $6 \mathrm{~h}$ marination induced an increase of its level. The fact that there was no inhibition with red wine as opposed to resveratrol (which totally inhibited MeIQ formation at a concentration of $0.1 \%$ and more) suggested that either the concentration of resveratrol in wine was too low to 568 achieve a good inhibition or an antagonist effect existed with other wine constituents. This 569 antagonistic effect could be due to the large amount of phenolic acids in red wine and in 570 particular gallic acid and caftaric acid (Van Leeuw, Kevers, Pincemail, Defraigne, \& 571 Dommes, 2014) that were both polyphenolic compounds with hydroxyl groups in ortho 572 position and electron withdrawing group, strongly deactivating, in meta position from the 
573 hydroxyl group. These phenolic acids, given their chemical structure, could also act as

574 inhibitors of MeIQ but would be less active than resveratrol due to the presence of ortho

575 deactivating group. As they were in large amounts in red wine, they could limit the inhibitory

576 effect of resveratrol by competitive agonist reaction. In the same way, the better MeIQ

577 inhibition of oregano than carvacrol (total inhibition $v s 33 \%$ of inhibition respectively at

578 concentration of $0.25 \%$ ) could suggest that the concentrations of pure carvacrol used for the

579 experiments were too low compare to that of oregano. Indeed as for the other natural

580 ingredients tested, the content of active principle in oregano was highly variable. Dambolena

581 et al. (2010) found that the relative percentage of carvacrol in oregano species varied from

582 trace amounts to $3.57 \%$. Another probable explanation of the difference of reactivity between

583 oregano and carvacrol against MeIQ formation could be that other oregano constituents

584 displayed an additive effect with carvacrol increasing the inhibition potential of MeIQ

585 formation. This agonist effect could be explained by the high amount of thymol, an isomer of

586 carvacrol, in common oregano species (such as Oreganum majorana and Oreganum vulgare)

587 (Dambolena, et al., 2010). The low inhibition displayed by caper formulation could be

588 explained by the varying amount of quercetin (from 0.03 to $1.45 \mathrm{mg} / \mathrm{g}$ depending on caper

589 origin) and by the fact that an important part of the quercetin load in caper sample was in the

590 form of flavonol glycosides (Inocencio, Rivera, Alcaraz, \& Tomás-Barberán, 2000). The

591 presence of sugar moieties added to the steric hindrance of the compound and could therefore

592 explain its lack of reactivity against HAA inhibition under this form.

593

594 5. Conclusion

595 The implementation of a method based on molecular modeling allowed the reasoned choice of

596 antioxidants inhibiting HAA formation (using analog design methods) and the explanation of

597 their reactivity (using structure-activity relationships). The first part of this study, based on 
medicinal chemistry approaches, highlighted the mandatory presence of a polyphenolic

599 moiety for HAA inhibition with two hydroxyl groups in meta position to enhance the reaction

600 of electrophilic aromatic substitution of the antioxidant on the Strecker aldehydes,

601 intermediates of the Maillard reaction forming thermic HAAs. The selected antioxidants, as to

602 know four phenolic active principles and four corresponding natural ingredients rich in these

603 active principles, were tested in ground beef patties cooked under common household

604 conditions. The inhibition study (Sections $4.2 \& 4.3$ ) highlighted that the reactivity of

605 antioxidants, as active principles or in natural ingredients, depended on the HAA targeted. It

606 was therefore difficult to conclude in a global manner about antioxidant capacity to inhibit

607 HAA formation in the meat matrix. Resveratrol was shown to be the most efficient in

608 inhibiting the HAAs studied but similar results were not found for red wine rich in this active

609 principle. On the contrary, oregano displayed the best inhibitory properties, suggesting

610 probable additive effect of other antioxidants present in this herb. This study pointed out the

611 importance to consider ingredients in their entirety. Indeed, molecular modeling permitted the

612 selection of inhibitors of HAA formation among a wide range of active principles but when

613 looking at natural ingredients known to be rich in these antioxidants, the results were not

614 linear. This highlighted the necessity to consider: 1) ingredient variety, as antioxidant

615 concentration varied from one species to another, as well as 2) the antioxidant environment in

616 the natural ingredient, in order to take into account potential agonist or antagonist effects on

617 the desired inhibitory activity. In the future it would be interesting to test different varieties of

618 a natural ingredient to take into account varietal diversity. The idea would be to see how to

619 make a reasoned choice of the ingredient and not only of the active principle. The use of

620 medicinal chemistry approaches developed in this study could be expanded to natural

621 ingredient composition. It would permit consideration of the impact of other components of

622 the natural ingredients, either agonist or antagonist, on HAA inhibition. 
623 While this study gave a method adapted from medicinal chemistry to select antioxidants

624 efficient in inhibiting HAA formation in proteinaceous food and explain their inhibitory

625 activity, the natural ingredients rich in these antioxidants should also be tested for their

626 organoleptic quality in meat preparations to assess consumer acceptance of these formulated

627 products. Indeed, finding inhibitory solutions is essential but useless if the corresponding

628 formulation is not accepted by consumers. Therefore the effects of the identified natural

629 antioxidant addition on the meat aroma profile were assessed in a second part of this research

630 work and compounds responsible for the differences between formulations were identified by

631 an original approach using hedonic rating, non-verbal analysis, quantitative descriptive

632 analysis, and gas chromatography-olfactometry. It would permit a comprehensive validation

633 considering both safety and sensory aspects.

634

6. Acknowledgements

636 This research was conducted as part of the MARMEAT project supported by the 637 TRANSFORM division of the French National Research Institute for Agriculture, Food and 638 the Environment (INRAE).

639

\section{Conflicts of interest}

641 The authors declare that there are no conflicts of interest.

\section{References}

644 Alaejos, M. S., \& Afonso, A. M. (2011). Factors that affect the content of heterocyclic aromatic amines in foods. Comprehensive Reviews in Food Science and Food Safety, $10(2), 52-108$.

Alland, C., Moreews, F., Boens, D., Carpentier, M., Chiusa, S., Lonquety, M., Renault, N., Wong, Y., Cantalloube, H., Chomilier, J., Hochez, J., Pothier, J., Villoutreix, B. O., Zagury, J. F., \& Tufféry, P. (2005). RPBS: a web resource for structural bioinformatics. Nucleic Acids Research, 33 (Web Server issue), W44-W49. 
Andricopulo, A. D., Salum, L. B., \& Abraham, D. J. (2009). Structure-Based Drug Design Strategies in Medicinal Chemistry. Current Topics in Medicinal Chemistry, 9(9), 771790.

Bohacek, R. S., McMartin, C., \& Guida, W. C. (1996). The art and practice of structure-based drug design: A molecular modeling perspective. Medicinal Research Reviews, 16(1), 3-50.

Busquets, R., Puignou, L., Galceran, M. T., \& Skog, K. (2006). Effect of red wine marinades on the formation of heterocyclic amines in fried chicken breast. J. Agric. Food Chem., $54,8376-8384$.

Cheng, K. W., Chen, F., \& Wang, M. (2007). Inhibitory activities of dietary phenolic compounds on heterocyclic amine formation in both chemical model system and beef patties. Mol Nutr Food Res, 51, 969-976.

Cheng, K. W., Wong, C. C., Chao, J., Lo, C., Chen, F., Chu, I. K., Che, C. M., Ho, C. T., \& Wang, M. (2009). Inhibition of mutagenic PhIP formation by epigallocatechin gallate via scavenging of phenylacetaldehyde. Mol Nutr Food Res, 53(6), 716-725.

Chevolleau, S., Touzet, C., Jamin, E., Tulliez, J., \& Debrauwer, L. (2007). Dosage par LCAPCI-MS/MS des amines aromatiques hétérocycliques formées lors de la cuisson des viandes. Science des Aliments, 27(6), 381-396.

Damašius, J., Venskutonis, P. R., Ferracane, R., \& Fogliano, V. (2011). Assessment of the influence of some spice extracts on the formation of heterocyclic amines in meat. Food Chemistry, 126, 149-156.

Dambolena, J. S., Zunino, M. P., Lucini, E. I., Olmedo, R., Banchio, E., Bima, P. J., \& Zygadlo, J. A. (2010). Total Phenolic Content, Radical Scavenging Properties, and Essential Oil Composition of Origanum Species from Different Populations. J Agric Food Chem, 58(2), 1115-1120.

Dong, H., Xian, Y., Li,, H., Bai, W., Zeng, X. (2020). Potential carcinogenic heterocyclic aromatic amines (HAAs) in foodstuffs: Formation, extraction, analytical methods, and mitigation strategie. Compr Rev Food Sci Food Saf., 19, 365-404.

Friedman, M., Zhu, L., Feinstein, Y., \& Ravishankar, S. (2009). Carvacrol facilitates heatinduced inactivation of Escherichia coli $\mathrm{O} 157: \mathrm{H} 7$ and inhibits formation of heterocyclic amines in grilled ground beef patties. J. Agric. Food Chem., 57(5), 18481853.

Gibis, M., \& Weiss, J. (2012). Antioxidant capacity and inhibitory effect of grape seed and rosemary extract in marinades on the formation of heterocyclic amines in fried beef patties. Food Chemistry, 134, 766-774.

Guy, P. A., Gremaud, E., Richoz, J., Turesky, R. J. (2000). Quantitative analysis of mutagenic heterocyclic aromatic amines in cooked meat using liquid chromatographyatmospheric pressure chemical ionisation tandem mass spectrometry. Journal of Chromatography A, 883 (1-2), 89-102.

Henning, S. M., Fajardo-Lira, C., Lee, H. W., Youssefian, A. A., Go, V. L. W., \& Heber, D. (2003). Catechin Content of 18 Teas and a Green Tea Extract Supplement Correlates With the Antioxidant Capacity. Nutr Cancer, 45(2), 226-235.

Inocencio, C., Rivera, D., Alcaraz, F., \& Tomás-Barberán, F. A. (2000). Flavonoid content of commercial capers (Capparis spinosa, C. sicula and C. orientalis) produced in mediterranean countries. European Food Research and Technology, 212(1), 70-74.

International Agency for Research on Cancer. IARC monographs on the evaluation of carcinogenic risks to humans, volume 114. Red meat and processed meat. Lyon, France: IARC; 2018.

Khan, M. R., Naushad, M., Alothman, Z. A., Algamdi, M. S., Alsohaimi, I. H., \& Ghfar, A. A. (2017). Effect of Natural Food Condiments on Carcinogenic/Mutagenic 
Heterocyclic Amines Formation in Thermally Processed Camel Meat. Journal of Food Processing and Preservation, 41(1).

Koes, D. R., \& Camacho, C. J. (2012). ZINCPharmer: pharmacophore search of the ZINC database. Nucleic Acids Research, 40(W1), W409-W414.

Kondjoyan, A., Chevolleau, S., Greve, E., Gatellier, P., Sante-Lhoutellier, V., Bruel, S., Touzet, C., Portanguen, S., \& Debrauwer, L. (2010). Formation of heterocyclic amines in slices of Longissimus thoracis beef muscle subjected to jets of superheated steam. Food Chemistry, 119(1), 19-26.

Lee, S. Y., Yim, D. G., Lee, D. Y., Kim, O. Y., Kang, H., J., Kim, H. S., Jang, A., Park, T. S., Sang Jin, K., Hur, S. J. (2020), Overview of the effect of natural products on reduction of potential carcinogenic substances in meat products, Trends in Food Science \& Technology, 99, 568-579.

Lipinski, C. A. (2004). Lead- and drug-like compounds: the rule-of-five revolution. Drug Discovery Today: Technologies, 1(4), 337-341.

Melo, A., Viegas, O., Petisca, C., Pinho, O., \& Ferreira, I. M. P. L. V. O. (2008). Effect of beer/red wine marinades on the formation of heterocyclic aromatic amines in pan-fried beef. J. Agric. Food Chem., 56(22), 10625-10632.

Meurillon, M., \& Engel, E. (2016). Mitigation strategies to reduce the impact of heterocyclic aromatic amines in proteinaceous foods. Trends in Food Science \& Technology, 50, 70-84.

Ni, W., McNaughton, L., LeMaster, D. M., Sinha, R., \& Turesky, R. J. (2008). Quantitation of 13 Heterocyclic Aromatic Amines in Cooked Beef, Pork, and Chicken by Liquid Chromatography-Electrospray Ionization/Tandem Mass Spectrometry. J Agric Food Chem, 56(1), 68-78.

Oguri, A., Suda, M., Totsuka, Y., Sugimura, T., \& Wakabayashi, K. (1998). Inhibitory effects of antioxidants on formation of heterocyclic amines. Mutat Res, 402, 237-245.

Planche, C., Ratel, J., Blinet, P., Mercier, F., Angénieux, M., Chafey, C., Zinck, J., Marchond, N., Chevolleau, S., Marchand, P., Dervilly-Pinel, G., Guérin, T., Debrauwer, L., \& Engel, E. (2017). Effects of pan cooking on micropollutants in meat. Food Chemistry, 232, 395-404.

Quelhas, I., Petisca, C., Viegas, O., Melo, A., Pinho, O., \& Ferreira, I. M. P. L. V. O. (2010). Effect of green tea marinades on the formation of heterocyclic aromatic amines and sensory quality of pan-fried beef. Food Chemistry, 122, 98-104.

Quintus, F., Sperandio, O., Grynberg, J., Petitjean, M., \& Tuffery, P. (2009). Ligand scaffold hopping combining 3D maximal substructure search and molecular similarity. $B M C$ Bioinformatics, 10(1), 245.

Rogers, D. J., \& Tanimoto, T. T. (1960). A computer program for classifying plants. Science (Washington), 132, 1115-1118.

Salazar, R., Arámbula-Villa, G., Hidalgo, F. J., \& Zamora, R. (2014). Structural characteristics that determine the inhibitory role of phenolic compounds on 2-amino1-methyl-6-phenylimidazo[4,5-b]pyridine (PhIP) formation. Food Chemistry, 151, 480-486.

Sperandio, O., Petitjean, M., \& Tuffery, P. (2009). wwLigCSRre: a 3D ligand-based server for hit identification and optimization. Nucleic Acids Research, 37 (Web Server issue), W504-W509.

Sterling, T., \& Irwin, J. J. (2015). ZINC 15 - Ligand Discovery for Everyone. Journal of Chemical Information and Modeling, 55(11), 2324-2337. 
Stervbo, U., Vang, O., \& Bonnesen, C. (2007). A review of the content of the putative chemopreventive phytoalexin resveratrol in red wine. Food Chemistry, 101(2), 449457.

Tengilimoglu-Metin, M., M., Hamzalioglu, A., Gokmen, V., Kizil, M. (2017). Inhibitory effect of hawthorn extract on heterocyclic aromatic amine formation in beef and chicken breast meat. Food Research International, 99(1), 586-595,Van Leeuw, R., Kevers, C., Pincemail, J., Defraigne, J. O., \& Dommes, J. (2014). Antioxidant capacity and phenolic composition of red wines from various grape varieties: Specificity of Pinot Noir. Journal of Food Composition and Analysis, 36(1), 40-50.

Wermuth, C.G. (2010). Analog Design, in Burger's Medicinal Chemistry, Drug Discovery and Development, $7^{\text {th }}$ edition. John Wiley \& Sons, Inc. 167-179.

Zeng, M., Li, Y., He, Z., Qin, F., Tao G., Zhang, S., Gao, H, Chen, J (2016). Discrimination and investigation of inhibitory patterns of flavonoids and phenolic acids on heterocyclic amine formation in chemical model systems by UPLC-MS profiling and chemometrics. European Food Research and Technology, 242 (3), 313-319.

Zheng, W., \& Lee, S.-A. (2009). Well-done meat intake, heterocyclic amine exposure, and cancer risk. Nutr Cancer, 61(4), 437-446.

Zhu, Q., Zhang, S., Wang, M. F., Chen, J., \& Zheng, Z. P. (2016). Inhibitory effects of selected dietary flavonoids on the formation of total heterocyclic amines and 2-amino1-methyl-6-phenylimidazo 4,5-b pyridine (PhIP) in roast beef patties and in chemical models. Food \& Function, 7(2), 1057-1066.

CRediT author statement

\section{Mitigation of heterocyclic aromatic amines in cooked meat}

\section{Part I: Informed selection of antioxidants based on molecular modeling}

Maïa MEURILLON - Conceptualization, Methodology, Validation, Formal analysis, Investigation, Writing - Original Draft, Writing - Review \& Editing, Visualization, Project administration, Funding acquisition

Magaly ANGENIEUX - Investigation

Frédéric MERCIER - Investigation

Patrick BLINET - Investigation

Laurent CHALOIN - Methodology, Writing - Review \& Editing

Sylvie CHEVOLLEAU- Investigation, Resources, Writing - Review \& Editing

Laurent DEBRAUWER - Investigation, Resources, Writing - Review \& Editing

Erwan ENGEL - Conceptualization, Formal analysis, Writing - Review \& Editing, Validation

\section{Declaration of interests}


$\bigotimes$ The authors declare that they have no known competing financial interests or personal relationships that could have appeared to influence the work reported in this paper.

$\square$ The authors declare the following financial interests/personal relationships which may be considered as potential competing interests:

\section{Highlights:}

- Analog design strategy to make a reasoned choice of antioxidants for HAA inhibition

- Determination of the structural properties required for inhibiting HAA formation

- Tests of HAA inhibition by 4 active principles and 4 natural ingredients

- Best formulations to reduce HAA formation 
<smiles>O=c1cc(-c2ccc(O)c(O)c2)oc2cc(O)cc(O)c12</smiles>

FLAVONOIDS

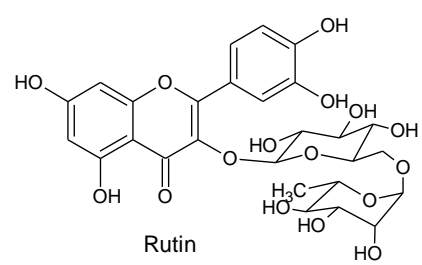

Rutin<smiles>Oc1ccc(/C=C/c2cc(O)cc(O)c2)cc1</smiles>

STILBENOIDS<smiles>CC(C)c1cc2c(c(O)c1O)C13CCCC(C)(C)C1CCC2O3</smiles>

Carnosol

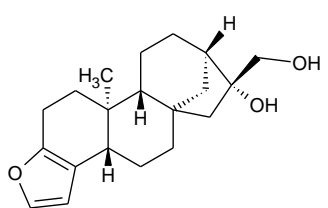

Cafestol<smiles>CC(C)c1cc2c(c(O)c1O)[C@@]1(O)[C@H](CCCC1(C)C)CC2</smiles>

Carnosic acid

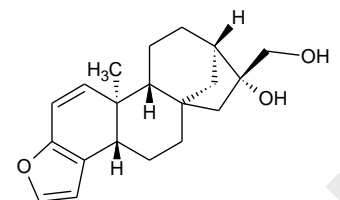

Kahweol<smiles>CC(C)c1cc2c(c(O)c1O)C13CCCC(C)(C)C1C(O2)C3O</smiles>

Rosmanol<smiles>Cc1ccc(C(C)C)cc1O</smiles>

Carvacrol

TERPENOIDS<smiles>Oc1cc(O)c2c(c1)OC(c1cc(O)c(O)c(O)c1)C(O)C2</smiles>

Epigallocatechin<smiles>O=C(OC1Cc2c(O)cc(O)cc2OC1c1cc(O)c(O)c(O)c1)c1cc(O)c(O)c(O)c1</smiles>

Epigallocatechin gallate

CATECHINS<smiles>Oc1cc(O)c2c(c1)O[C@H](c1ccc(O)c(O)c1)[C@H](O)C2</smiles>

Epicatechin<smiles></smiles>

Vitamin E<smiles>Cc1ncc(CO)c(CN)c1O</smiles>

Pyridoxamin (vitamin B6)

VITAMINS<smiles>C=CCS[S+]([O-])CC=C</smiles>

Allicin<smiles>C=CCSSCC=C</smiles>

Diallyl disulfide

Figure 1. Chemical structure of the most promising inhibitors of HAAs (Meurillon \& Engel 
813

a)

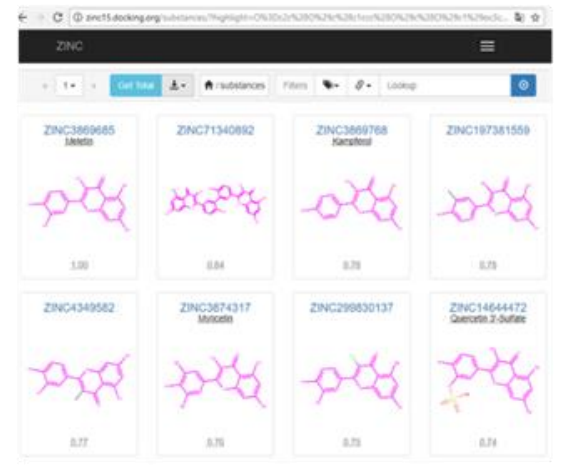

c)

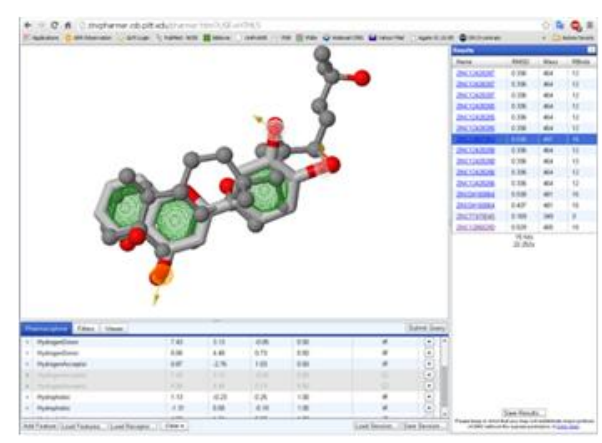

b)

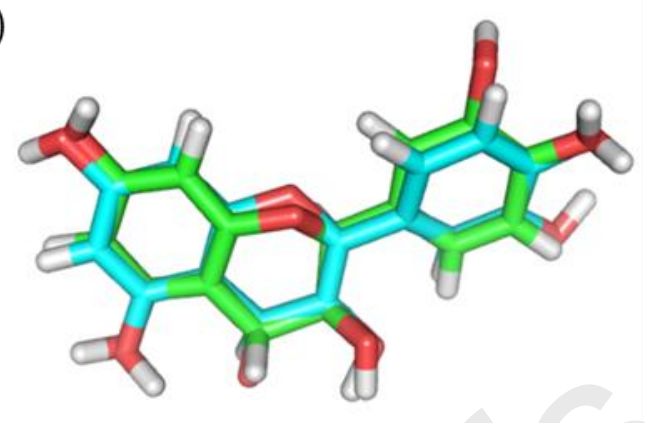

d)

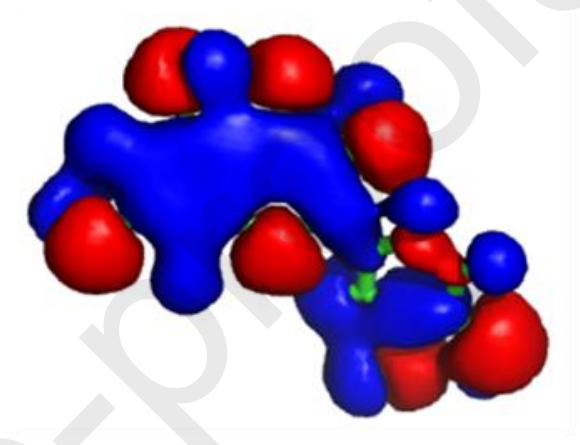

816 Figure 2. The different steps of molecular modelling and analog search based on quercetin scaffold. a)

817 Similarity search based on Tanimoto index (based on fingerprints defined only by the chemical formula)

818 allowing collection of all compounds having 70\% similarity with quercetin, b) Scaffold hopping based on 3D

819 shape similarity and physicochemical properties permitting enrichment of compound libraries with similar core structures, c) Pharmacophore model defined by the main molecular features of quercetin (aromatic cycle,

821 hydrogen bond donors and acceptors) allowing the screening of chemical databases for compounds fulfilling

822 these criteria, d) Electrostatic potential surface determination to help in defining organic reactivity by

823 examining electron distribution within the chemical structure. Electrostatic potential surface was computed using

824 Adaptive Poisson-Boltzmann Solver with a probe radius of 1.4 A. Positive (blue) and negative (red) isosurfaces 825 at $\pm 5 \mathrm{kT} / \mathrm{e}$ and visualized by VMD. 


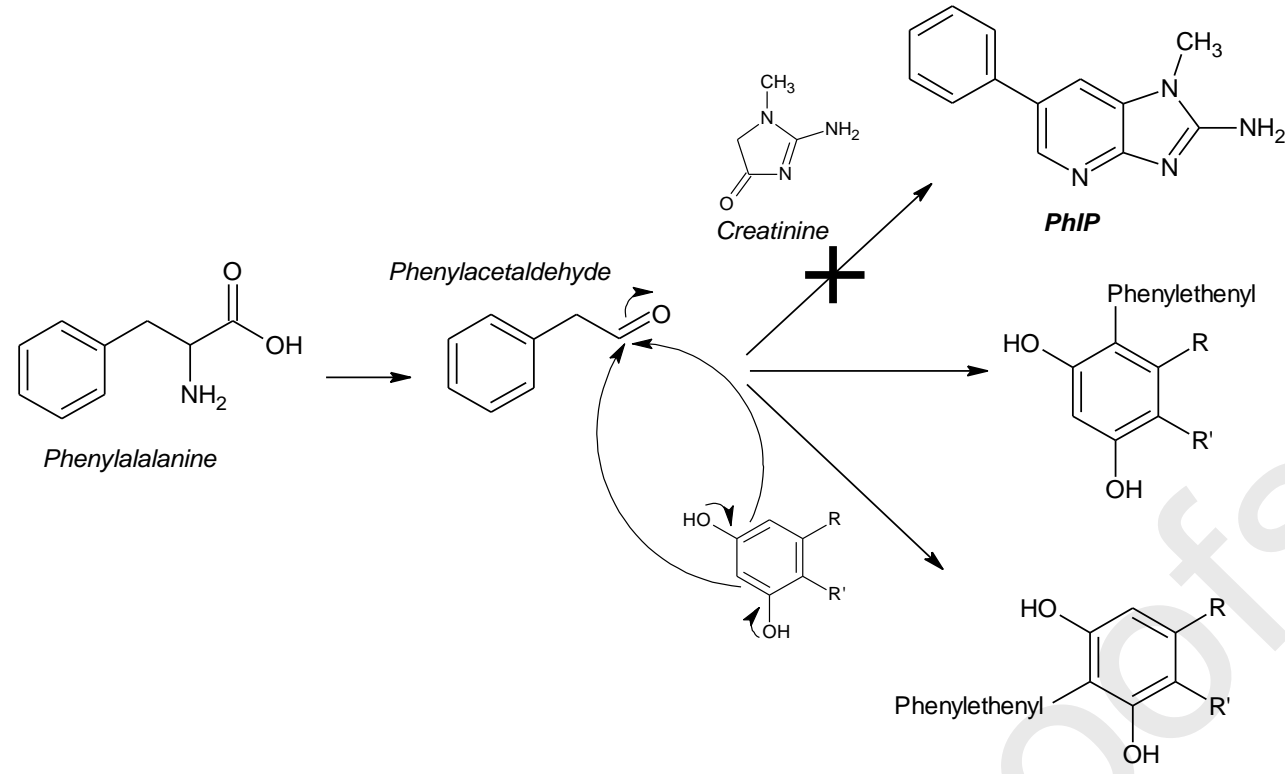

Figure 3. Postulated pathways for inhibitory activity of polyphenolic compounds on $\mathrm{PhIP}$

Table 1. Number of structural analogs displaying a Tanimoto coefficient $>0.7$ and number of

834 functional analogs given by scaffold hopping based on 3D and physicochemical similarity for

835 each antioxidant described in the literature as a HAA inhibitor.

\begin{tabular}{|c|c|c|}
\hline Compounds & Structural analogs ${ }^{\mathrm{a}}$ & Functional analogs $^{b}$ \\
\hline Resveratrol & $\begin{array}{l}17 \text { different compounds (47 compounds including different } \\
\text { diastereoisomers) }\end{array}$ & 17 compounds \\
\hline Luteolin & 36 different compounds & 11 compounds \\
\hline Quercetin & 26 different compounds & 4 compounds \\
\hline Rutin & 1 compound with different diastereoisomers & $0(\& 0$ with a Zscore $>2)$ \\
\hline Carnosol & $\begin{array}{l}8 \text { different compounds ( } 51 \text { compounds including different } \\
\text { diastereoisomers) }\end{array}$ & 0 (\& 5 with a Zscore $>2)$ \\
\hline Carnosic acid & $\begin{array}{l}9 \text { different compounds (37 compounds including different } \\
\text { diastereoisomers) }\end{array}$ & 0 (\& 7 with a Zscore $>2$ ) \\
\hline Rosmanol & $\begin{array}{l}11 \text { different compounds ( } 84 \text { compounds including different } \\
\text { diastereoisomers) }\end{array}$ & 0 (\& 1 with a Zscore $>2)$ \\
\hline Cafestol & $\begin{array}{l}6 \text { different compounds (100 compounds including different } \\
\text { diastereoisomers) }\end{array}$ & 0 (\& 3 with a Zscore $>2)$ \\
\hline Kahweol & $\begin{array}{l}3 \text { different compounds ( } 57 \text { compounds including different } \\
\text { diastereoisomers) }\end{array}$ & 0 (\& 5 with a Zscore $>2)$ \\
\hline Carvacrol & 5 different compounds & 41 compounds \\
\hline Epigallocatechin & $\begin{array}{l}11 \text { different compounds ( } 46 \text { compounds including different } \\
\text { diastereoisomers) }\end{array}$ & 1 compound \\
\hline $\begin{array}{l}\text { Epigallocatechin } \\
\text { gallate }\end{array}$ & $\begin{array}{l}28 \text { different compounds (100 compounds including different } \\
\text { diastereoisomers) }\end{array}$ & 0 (\& 4 with a Zscore $>2)$ \\
\hline
\end{tabular}




\begin{tabular}{|l|l|l|}
\hline Epicatechin & $\begin{array}{l}\text { 20 different compounds (82 compounds including different } \\
\text { diastereoisomers) }\end{array}$ & $\mathbf{7}$ compounds \\
\hline Vitamin E & $\begin{array}{l}\mathbf{1 4} \text { different compounds (100 compounds including different } \\
\text { diastereoisomers) }\end{array}$ & $0(\& 0$ with a Zscore $>2)$ \\
\hline Pyridoxamine & $\mathbf{1 7}$ different compounds & $0(\& 26$ with a Zscore $>2)$ \\
\hline Allicin & 1 compound with different diastereoisomers & $0(\& 0$ with a Zscore $>2)$ \\
\hline Diallyl sulfide & $\mathbf{7}$ different compounds & $0(\& 1$ with a Zscore $>2)$ \\
\hline
\end{tabular}

Table 2. Amount of the different HAAs found in cooked ground beef patties formulated with

841 or without antioxidants.

842

843

844

845

846

847

848

849

850

851 or without natural ingredients. difference to control value, $p<0.001$.

$\begin{array}{lrrrrr}\text { Samples } & \text { IQ } & \text { MelQx } & \text { MelQ } & \text { 4,8-DiMelQx } & \text { PhIP } \\ \text { Control } & \text { N.D. } & 7.2 \pm 2.2 & 0.4 \pm 0.1 & 0.7 \pm 0.3 & 2.3 \pm 0.9 \\ \text { Epicatechin 0.1\% } & \text { N.D. } & 10.8 \pm 1.7 & 0.3 \pm 0.1 & 1.1 \pm 0.2 & 3.1 \pm 0.9 \\ \text { Epicatechin 0.25\% } & \text { N.D. } & 10.6 \pm 4.1 & \text { N.D.*** } & 1.1 \pm 0.4 & 2.3 \pm 1.5 \\ \text { Epicatechin 0.5\% } & \text { N.D. } & 8.9 \pm 3.3 & \text { N.D.*** } & 0.8 \pm 0.3 & 1.0 \pm 0.4 \\ \text { Resveratrol 0.1\% } & \text { N.D. } & 4.9 \pm 1.1^{*} & \text { N.D.*** } & 0.5 \pm 0.2 & 0.8 \pm 0.2^{* *} \\ \text { Resveratrol 0.25\% } & \text { N.D. } & 4.5 \pm 0.6^{*} & \text { N.D.*** } & 0.5 \pm 0.1 & 0.7 \pm 0.1^{* *} \\ \text { Resveratrol 0.5\% } & \text { N.D. } & 8.2 \pm 1.6 & \text { N.D.*** } & 0.8 \pm 0.2 & 1.9 \pm 0.9 \\ \text { Quercetin 0.1\% } & \text { N.D. } & 8.9 \pm 2.6 & 0.3 \pm 0.0 & 0.8 \pm 0.3 & 2.4 \pm 0.9 \\ \text { Quercetin 0.25\% } & \text { N.D. } & 11.0 \pm 6.3 & 0.3 \pm 0.2 & 1.0 \pm 0.5 & 3.1 \pm 2.0 \\ \text { Quercetin 0.5\% } & \text { N.D. } & 5.6 \pm 0.8 & \text { N.D. } & 0.5 \pm 0.0 & 1.0 \pm 0.2 \\ \text { Carvacrol 0.1\% } & \text { N.D. } & 6.1 \pm 0.5 & 0.3 \pm 0.1 & 0.6 \pm 0.0 & 1.5 \pm 0.2 \\ \text { Carvacrol 0.25\% } & \text { N.D. } & 5.1 \pm 0.4^{* *} & 0.3 \pm 0.1 & 0.5 \pm 0.1 & 1.2 \pm 0.1^{*} \\ \text { Carvacrol 0.5\% } & \text { N.D. } & 6.1 \pm 1.2 & 0.3 \pm 0.1 & 0.6 \pm 0.1 & 1.4 \pm 0.9\end{array}$

Values expressed in $\mathrm{ng} / \mathrm{g}$ of freeze-dried product; each experiment was repeated 3 times; The detection and quantification limits (expressed in ng/g of freeze-dried product) were, respectively, 0.02 and 0.2 for PhIP, IQ and 4,8-DiMeIQx and 0.05 and 0.2 for MeIQx and MeIQ; N.D.: not detected; *: significant difference to control value, $p<0.05$; **: significant difference to control value, $p<0.01$; **: significant

$\begin{array}{lrrrrr}\text { Samples } & \text { IQ } & \text { MelQx } & \text { MelQ } & \text { 4,8-DiMelQx } & \text { PhIP } \\ \text { Control } & \text { N.D. } & 7.2 \pm 2.2 & 0.4 \pm 0.1 & 0.7 \pm 0.3 & 2.3 \pm 0.9 \\ \text { Green Tea 2 h } & \text { N.D. } & 6.2 \pm 1.7 & \text { N.D.*** } & 0.6 \pm 0.0 & 2.1 \pm 0.5 \\ \text { Green Tea 4 h } & \text { N.D. } & 4.9 \pm 0.7 & \text { N.D.*** } & 0.6 \pm 0.1 & 1.7 \pm 0.9 \\ \text { Green Tea 6 h } & \text { N.D. } & 5.9 \pm 2.2 & 0.3 \pm 0.0 & 0.6 \pm 0.2 & 2.1 \pm 1.5 \\ \text { Red Wine 2 h } & \text { N.D. } & 7.1 \pm 2.1 & 0.3 \pm 0.0 & 0.8 \pm 0.2 & 1.6 \pm 0.7 \\ \text { Red Wine 4 h } & \text { N.D. } & 8.4 \pm 2.8 & 0.4 \pm 0.0 & 1.0 \pm 0.3 & 1.6 \pm 0.7\end{array}$




$\begin{array}{llllll}\text { Red Wine 6h } & \text { N.D. } & 8.2 \pm 1.4 & 0.3 \pm 0.1 & 1.0 \pm 0.1 & 1.7 \pm 0.6 \\ \text { Caper 0.1\% } & \text { N.D. } & 5.6 \pm 1.2 & 0.3 \pm 0.0 & 0.6 \pm 0.1 & 1.2 \pm 0.5 \\ \text { Caper 0.25\% } & \text { N.D. } & 7.0 \pm 3.7 & 0.2 \pm 0.1 & 0.7 \pm 0.4 & 2.2 \pm 1.5 \\ \text { Caper 0.5\% } & \text { N.D. } & 7.1 \pm 2.4 & 0.2 \pm 0.1 & 0.7 \pm 0.2 & 1.8 \pm 0.6 \\ \text { Oregano 0.1\% } & \text { N.D. } & 9.2 \pm 3.2 & 0.5 \pm 0.1 & 0.8 \pm 0.2 & 3.0 \pm 1.4 \\ \text { Oregano 0.25\% } & \text { N.D. } & 4.6 \pm 0.3 & \text { N.D. } & \\ \text { Oregano 0.5\% } & \text { N.D. } & 5.7 \pm 0.9 & \text { N.D. } & 0.5 \pm 0.1 & 1.0 \pm 0.2 \\ & & & & 0.6 \pm 0.1 & 1.1 \pm 0.3\end{array}$

853 Values expressed in $\mathrm{ng} / \mathrm{g}$ of freeze-dried product; each experiment was repeated 3 times; Red wine is rich in resveratrol, green tea in 854 epicatechin, caper in quercetin and oregano in carvacrol; The detection and quantification limits (expressed in ng/g of freeze-dried product) 855 were, respectively, 0.02 and 0.2 for PhIP, IQ and 4,8-DiMeIQx and 0.05 and 0.2 for MeIQx and MeIQ; N.D.: not detected; *: significant 856 difference to control value, $p<0.05$; **: significant difference to control value, $p<0.01$; ***: significant difference to control value, $p<$ $857 \quad 0.001$. 